\title{
The terminus of Hubbard Glacier, Alaska
}

\author{
ROBERT M. KRIMMEL \\ Ice and Climate Project, U.S. Geological Survey, University of Puget Sound, Tacoma, WA 98416, U.S.A. \\ AND D. C. TRABANT \\ U.S. Geological Survey, 800 Yukon Drive, Fairbanks, AK 99775, U.S.A.
}

\begin{abstract}
Hubbard Glacier advanced across the entrance of Russell Fiord in May 1986, transforming the fiord into a lake, which began filling with fresh water. The dam failed in October 1986. The calving terminus of Hubbard Glacier has been mapped with increasing frequency for nearly a century. A mapping interval of a few years establishes that the terminus has made a slow, but accelerating, advance. Recently the terminus has been mapped several times per month using vertical photography, ground surveys, and time-lapse cameras. At this frequency of observation, the terminus position is found to fluctuate seasonally. These seasonal fluctuations are compared with those of Columbia Glacier, where a longer detailed record is available. Although Columbia Glacier is now undergoing a drastic retreat, it continues to have seasonal length changes similar to those it experienced before the retreat began. The lengths of both Columbia and Hubbard Glaciers are extended in the spring, and retracted in the fall. The relatively long period of record for Columbia Glacier shows consistent seasonal variation in length and, when compared with the short period of record for Hubbard Glacier, suggests that there are consistent seasonal differences in length at Hubbard also. The lower Hubbard Glacier diverges, feeding ice into Disenchantment Bay and Russell Fiord, and advances and retreats synchronously over most of its width. The tidal current, which passes through the $250-500 \mathrm{~m}$ wide entrance to Russell Fiord, does not affect the seasonal advance and retreat in that area significantly.
\end{abstract}

\section{INTRODUCTION}

Hubbard Glacier has a history of advance during the 20th century (Field, 1975). An advance of several kilometers, which began sometime before the end of the 19th century, closed Russell Fiord in May 1986 (Mayo, 1988). This closure lasted until the following October, when the ice dam failed. This event resulted in increased public awareness of a possible long-term closure and was the impetus for beginning a project to monitor Hubbard Glacier, with the goal of predicting its future behavior.

Several factors complicate a prediction. Hubbard Glacier terminus calves into Disenchantment Bay and Russell Fiord (Fig. 1). Below $800 \mathrm{~m}$ altitude, the glacier surface is dominated by ice from Hubbard Glacier (65\%) and the Valerie Glacier tributary $(35 \%)$. Ice flow diverges in the lower part of the glacier, with an estimated $80 \%$ of the ice directed toward Disenchantment Bay, and the remainder toward Russell Fiord. Instabilities in the flow of tributary glaciers add additional complexity. "Seattle" Glacier (unoffical name) surges, Valerie Glacier is known to have had speed instabilities (Mayo, 1988) and Hubbard Glacier has speed pulses as well (Trabant and others, 1991). Approximately $4 \%$ of the equilibrium line mass flux is lost to surface ablation, and the remaining $96 \%$ goes into increased thickness or is lost by calving (Trabant and others, 1991). The ice near the terminus thins as it approaches and passes over the terminal moraine shoal. There is a strong tidal current through "Sand Dab Passage" (unofficial name). In addition, basal sliding is not easily modeled, the mechanism of calving is not well defined, and future weather and climate are uncertain.

The prediction of Trabant and others (1991) for Hubbard Glacier relied on a simple extrapolation of trends and a qualitative analysis of observations at Hubbard and other tidewater glaciers. Trabant and others (1991) estimated a 50\% chance of a new closure of Russell Fiord occurring within three years. This was based primarily on an extrapolation of the long-term trend in terminus advance. It was also predicted that the most likely time of year for a new closure was the spring. This was based on about ten years of observations at Columbia Glacier, where a regular seasonal cycle of the terminus was documented: the glacier tended to have maximum length in the late spring and minimum length in late fall (Krimmel and Vaughn, 1987). In addition, episodic calving sometimes resulted in major changes in the terminus shape over the period of a few days, especially in the fall when calving tended to be greatest.

Before 1986 very little was known about the seasonal or shorter term changes in the terminus of Hubbard 


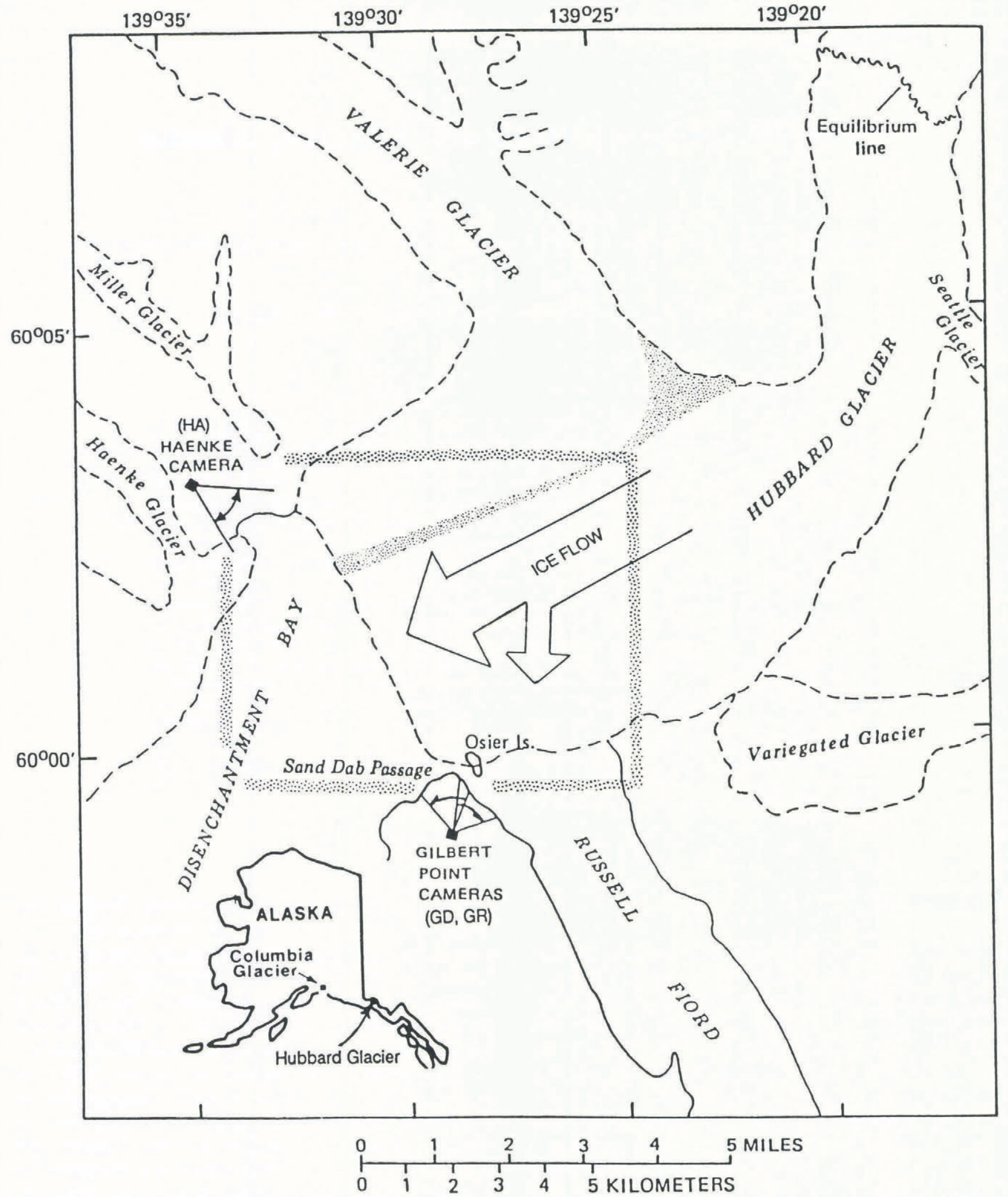

Fig. 1. The lower part of Hubbard and Valerie Glaciers and the locations of the time-lapse cameras. Box indicates area enlarged in Figure 4.

Glacier. This report will discuss the short-term changes in the position and shape of the Hubbard Glacier terminus, which is a key part of the prediction made by Trabant and others (1991). Results from the analysis of time-lapse photos from cameras placed to record short-term changes in the terminus will be emphasized.

\section{TERMINUS OBSERVATIONS}

Observations of the Hubbard Glacier terminus have been increasingly frequent since the late 19 th century. Terminus maps, separated by a year or more, show the general changes in glacier position. The 1986 closure 


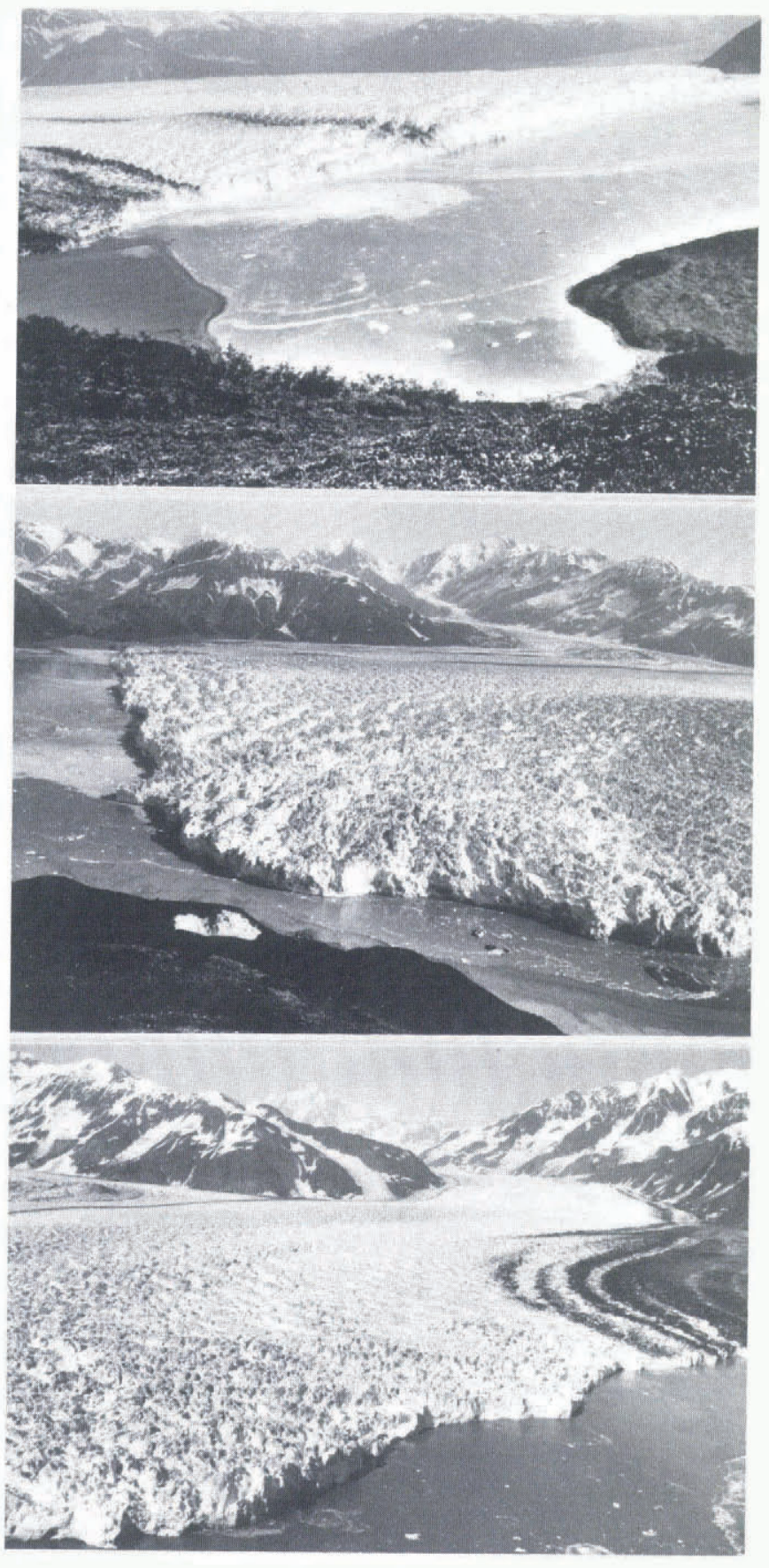

Fig. 2. A frame from each of the three time-lapse cameras: top - from Haenke (HA) toward Disenchantment Bay, center - from Gilbert toward Disenchantment Bay (GD) and bottom - from Gilbert toward Russell Fiord (GR).

formed and collapsed in less than six months, indicating that a more frequent temporal resolution is required to observe the events that lead to a closure. In 1986 frequent observations were begun using optical surveys, aerial photography, and time-lapse terrestrial cameras. Each of these methods has its particular good or bad characteristics. Optical surveys require people and equipment in the field, and usually result in a spatially coarse set of points along the terminus. Aerial photography is expensive, but results in a permanent and precise record of the conditions at an instant in time. Time-lapse cameras offer a frequent record of conditions, but must be maintained with field visits.

\section{TIME-LAPSE GAMERAS AT HUBBARD GLAGIER}

Automatic cameras have been used successfully to record glacier motion and terminus position elsewhere (Krimmel and Rasmussen, 1986), and this was one of the methods used to record changes in the Hubbard Glacier terminus. Three wide-angle cameras were required to obtain coverage of all critical areas. One of these was placed on a ridge north of the terminus (HA, Fig. 1), and two were placed on a ridge between Disenchantment Bay and Russell Fiord (GD and GR, Fig. 1). The focal length of the HA, GD, and GR cameras were 35,28 , and $35 \mathrm{~mm}$ respectively. HA was installed in November of 1987, and GD and GR were installed respectively in the summer and fall of 1988. Each camera holds 100 frames of color transparency film, and takes one frame every 2 days. Two visits each year are required to change film and batteries. The camera success rate from the fall of 1987 to late August of 1990 (total number of days the cameras worked divided by the total number of days that the cameras were installed, $1357 / 2247$ ) is $60 \%$. The most common cause of failure was low temperatures during winter. The camera enclosures were heated with propane-fired catalytic heaters, but these were not reliable. Another frequent cause of failure arose from the complexity of the programmable data backs and intervalometers, which were sometimes set incorrectly. Usable photos were obtained about $50 \%$ of the time despite all failures, bad weather, and burial by snow. An example frame from each camera location is shown in Figure 2. This report will discuss results for the period from late July 1988 to early September 1989.

Digital information was extracted from the original film under $8 \times$ magnification using a 15 micrometer digitization tablet. The film plane locations $(v, w)$ of several landmarks and of points along the ice-tide contact (at the rate of one each $0.1 \mathrm{~mm}$ of cursor travel, about 300 points on a typical frame) were recorded. All coordinates were referenced to the center of the image with the axes parallel to the frame edges.

The orientation angles (which are the horizontal, lateral, and vertical angles of the camera orientation relative to a rectangular coordinate system with the camera focal point at $0,0,0)$ of the cameras were determined using methods explained by Krimmel and Rasmussen (1986). The tedious orientation process involves a "man-the-loop" iterating procedure. If it can be determined that the cameras do not move between frames, then one orientation can suffice for many frames. It is expected that the cameras will change orientation after each visit; and snow load, animals, wind and people can change the orientation between film changes.

When the camera is stable, landmark points remain in the same location relative to the frame centers. This is checked routinely by plotting the deviation from the mean of the film plane coordinates for each of the landmark points (5 or 6 , depending on the camera). Landmark deviations indicate that the cameras were not 


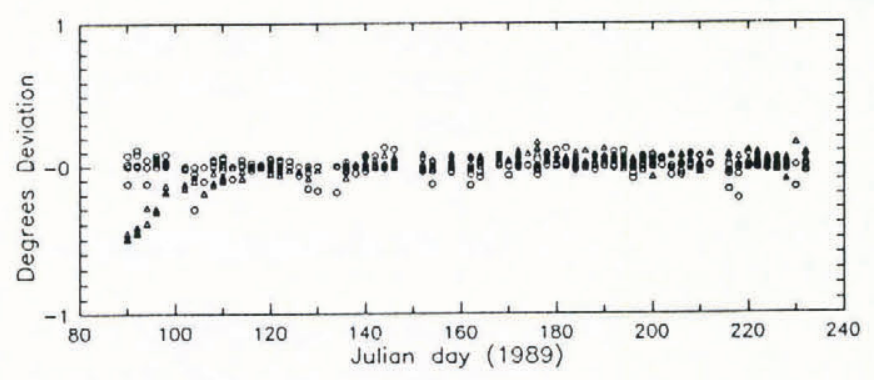

Figure 3. The stability of the GR camera. Five landmark points were used to orient the GR camera. The film-plane coordinates $(v, w)$ of each were measured whenever visible. On each day there are five possible $v$ symbols (circles) and five $w$ symbols (triangles), but clouds often prevent some or all measurements. The position of the symbols along the ordinate is the deviation from the average of all values for the particular landmark point. For the 1989 day 88-232 period the camera was stable in rotation about the vertical axis (v), and from day 110-232 was stable about the lateral axis (w), but from 88-105 it was not stable about the lateral axis.

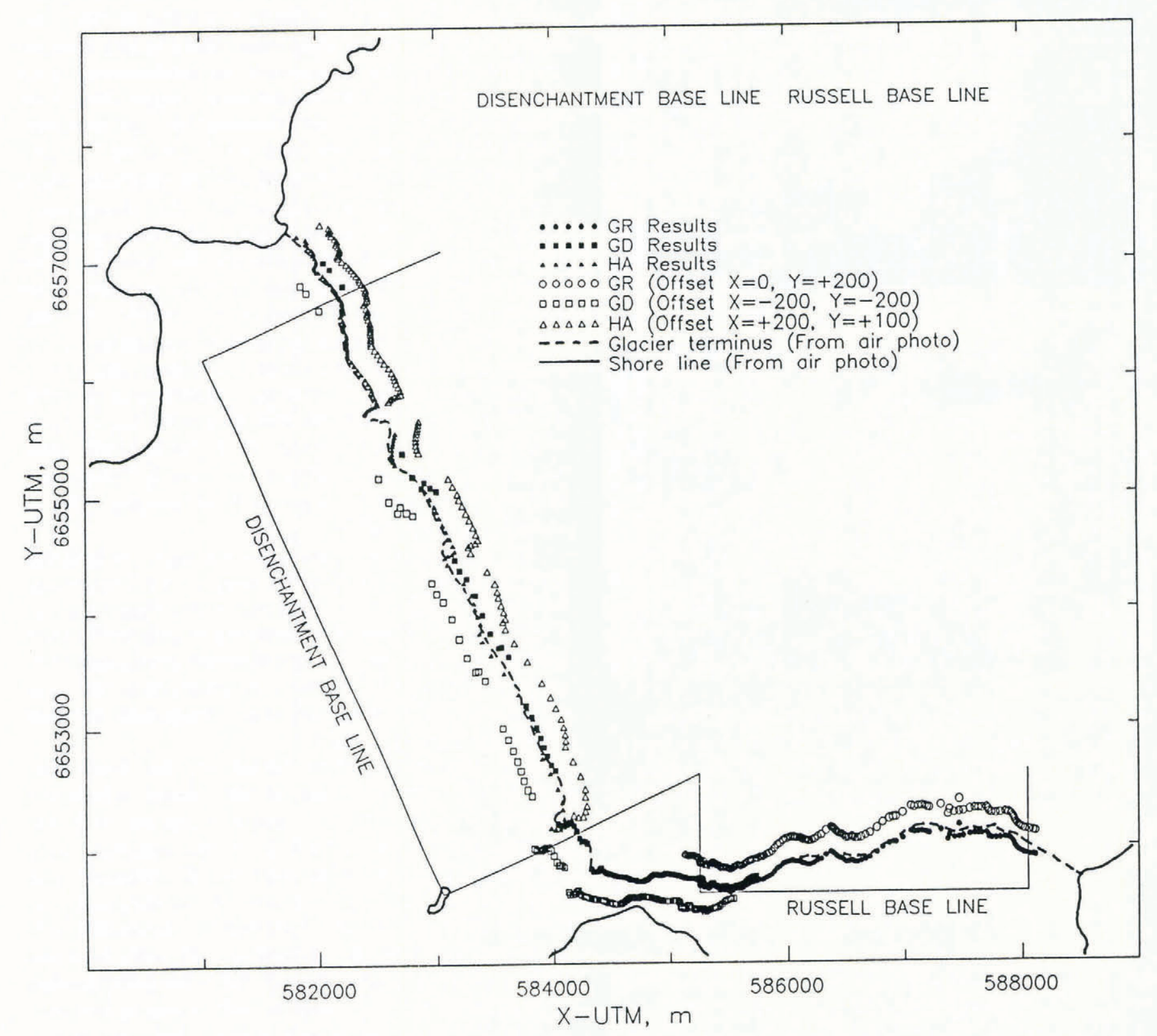

Fig. 4. A comparison of the terminus position as determined from the three time-lapse cameras and from vertical photography on 28 June 1989. Results from the time-lapse cameras HA (28 June 1989), GD (30 June 1989), and GR (27 June 1989) are each shown twice: once as a solid form at the actual position and once as an open form offset by the indicated amount. The offsets are provided only to separate the points derived from the different cameras. The actual points cluster on the terminus as mapped from the vertical photos, the dashed line. The Disenchantment and Russell base lines are discussed in the text. 
stable. Figure 3 shows the landmark deviations for camera GR, which suggest stability in $v$ for the entire period from day 88 to day 232 ; but in $w$ there was some camera movement prior to day 105 . The camera mounts used would explain an independence in stability of $v$ and $w$. Deviations from the mean during periods of stability are typically $\pm 0.1 \mathrm{~mm}$, which is mostly a random error in identifying the landmarks (which are natural features such as mountain peaks). The $v$ and $w$ of each landmark were taken as the mean of the values during periods of stability after removing outliers.

The iteration process produces an angle with an error value which is a function of the rotation of the camera about the true vertical axis and the true horizontal lateral axis. The goal is to minimize the error function. It is possible to iterate until the error is about $0.01^{\circ}$. A potential source of error in this process is the mislocation of landmark points. The Universal Transverse Mercator (UTM) coordinates of the landmark points were determined from U.S. Geological Survey 1:63360 topographic maps, and could easily be in error by $100 \mathrm{~m}$.

The apparent error in the location of a terminus point at a distance of $5 \mathrm{~km}$, with a vertical angle of $6^{\circ}$, is about $1 \mathrm{~m}$ per $0.01^{\circ}$ of horizontal angle error, and about $10 \mathrm{~m}$ per $0.01^{\circ}$ of vertical angle error. The terminus of the glacier is generally less than $5 \mathrm{~km}$ from the cameras, therefore most of the terminus points have smaller errors.

The orientation angles are then used to determine the location of sea-level (terminus) points, again using the method given by Krimmel and Rasmussen (1986). The location of the terminus points is dependent on the elevation of the camera above sea level. No correction was made for the tidal range of about $5 \mathrm{~m}$. Tidal variations could result in an error of several tens of meters in the horizontal location of terminus points in a direction toward or away from the cameras. This error is not critical because the terminus advance or retreat is laterally across the photo frame, rather than toward or away from the focal point, and the cameras were generally pointed in that favorable direction. It was only near Gilbert Point that the terminus position change was in line with the optical axis of the camera, but in that zone potential tidal error was reduced because the vertical angles are relatively large, and the distance short.

In practice, a simple way to assess the cumulative errors is to look qualitatively at the results. There are two convenient tests to check the methodology. Terminus positions derived from different cameras may be compared with each other where there is overlapping coverage, and results may be compared with the terminus positions measured on concurrent vertical photography. Figure 4 shows results from each camera on nearly coincidental dates and results from the vertical photos on 28 June 1989.

\section{GLAGIER LENGTH}

Glacier length, which is approximately synonymous with the glacier terminus position, is an easily reported, onedimensional value. The reported length depends on some method of determining a representative average across the width of the rapidly changing, irregular terminus. At
Hubbard, because the flow is diverging at the terminus, it was decided to determine two lengths, one as the glacier flows into Disenchantment Bay and the other as the glacier flows into Russell Fiord. The width-averaging method is similar for both, and depends on the area of a polygon. The base side of this polygon (Fig. 4) is of constant length and location, approximately perpendicular to the glacier flowline, and arbitrarily set at some convenient distance from the head of the glacier. Two side lines of the polygon are perpendicular to the ends of the base line and intersect the terminus. The rest of the polygon consists of numerous points along the terminus, one of which must lie on each of the two side lines, and the remainder of which must lie between the side lines. The width-averaged glacier length is the difference between the polygon area divided by the base line length, and the location of the base line relative to the glacier head. This method can be easily applied using terminus shapes determined from the time-lapse cameras, as well as those determined by optical surveys or from aerial photography.

The most critical part of the Hubbard terminus, as far as closure is concerned, is that part which is directly adjacent to "Sand Dab Passage" (Fig. 1). The width of the passage is the most easily reported value representing the relation between Hubbard Glacier and the closing of Russell Fiord. The reported passage width is the minimum distance between Gilbert Point and the glacier terminus across "Sand Dab Passage". The glacier length at Gilbert Point ( $123.0 \mathrm{~km}$ from the glacier head), is $123.0 \mathrm{~km}$ minus the passage width. Lengths for Hubbard Glacier as directed toward Disenchantment Bay, Russell Fiord, and Gilbert Point are shown in Figure 5.

\section{DISCUSSION}

An inherent quality of this method used to derive terminus shapes monoscopically is shown in Figure 4: the spatial density of calculated locations decreases as the distance to the target area increases. This is expected because the scale decreases with distance. Errors also, logically enough, increase with distance. When two cameras view the same subject, but from opposing perspectives, as was the case with cameras HA and GD viewing the Disenchantment terminus, a method of merging the overlapping data sets must be devised. An attempt was made to combine the data sets automatically, with an inverse distance-weighted factor to accommodate the change in error as distance increased, but this proved to be difficult. Instead, the overlapping data were combined graphically by overlaying the positions of the plotted points and redigitizing the position of the terminus to use in the calculation of the glacier length.

The terminus shapes derived from the terrestrial timelapse cameras agree well with those derived from aerial photography. The differences between the two methods, when the width-averaged glacier lengths are compared, are usually less than $20 \mathrm{~m}$ and can be attributed to two factors. First, from the aerial vantage, the actual tide-ice contact is often only visible in one half of the stereo model, resulting in a systematic error of a few meters and 


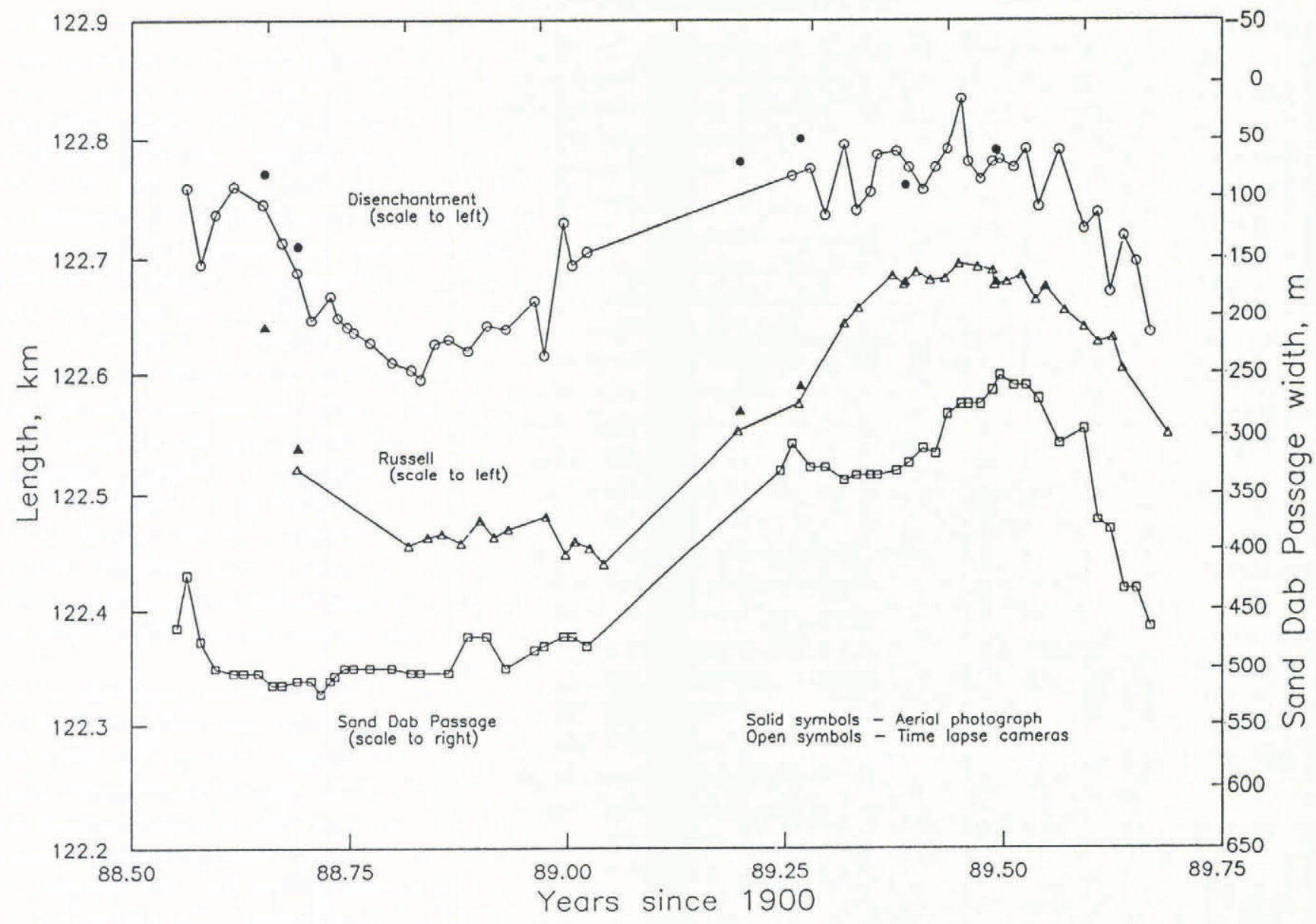

Fig. 5. The length of Hubbard Glacier as it flows toward Disenchantment Bay and Russell Fiord, and the width of "Sand Dab Passage". The ordinate scale indicating the width of the passage decreases upward so that a direct comparison can be made with the glacier length. The short-term scatter, particularly for the Disenchantment terminus, results from errors in the measurements, rather than changes in the glacier.

likewise, from the terrestrial cameras, portions of the terminus are out of view, requiring interpolation to complete the terminus shape. Second, because the timelapse cameras did not view the northern part of the Disenchantment terminus, the polygon base line used in the width averaging is $5 \mathrm{~km}$ wide, rather than the $6 \mathrm{~km}$ width used with the aerial data. This change in base line length could also result in minor differences when comparing the data.

The time-lapse cameras have enabled the construction of frequent terminus maps. During the 14 month period of this analysis, there was a seasonal trend in the Hubbard Glacier length which is similar to the persistent seasonal trends seen at Columbia Glacier (Krimmel and Vaughn, 1987), with an extended length in the spring, and a reduced length in the fall. At Hubbard there was a seasonal length change of approximately $200 \mathrm{~m}$, and at Columbia, before the drastic retreat, a seasonal change of about $300 \mathrm{~m}$. The similarity between the seasonal changes in length of the two glaciers adds credibility to the prediction by Trabant and others (1991) that the most likely time of year for a Russell Fiord closure is late spring.

The width-averaged lengths and the inverse of the "Sand Dab Passage" widths correlate well; that is, the complete Hubbard terminus advances or retreats synchronously (Fig. 5). There may be minor local embayments or advances, but generally the entire terminus is apparently influenced by the same seasonally dependent ice-flow and calving mechanisms.

There has been speculation that the tidal current through "Sand Dab Passage" could erode the ice face, thus slowing the advance toward the closure point (Trabant and others, 1991). This current is estimated to average $5 \mathrm{~m} \mathrm{~s}^{-1}$, but may be as fast as $10 \mathrm{~m} \mathrm{~s}^{-1}$. This flow, which reverses four times daily, will be faster during times when the channel width is reduced and when there is extreme tide change. During the winter and spring, the terminus advanced equally into the narrows, into Disenchantment Bay and into Russell Fiord, despite this current. This advance indicates that either the current does not increase calving, or that, if it did increase calving, then there must have been more rapid ice flow toward the narrows than in other parts of the terminus. There was a short period of increased ice speed during mid-1989 (Trabant and others, 1991), but this pulse was measured at a point about $15 \mathrm{~km}$ above the terminus, and appeared to influence the entire width of the terminus. We conclude that the current in "Sand Dab Passage" 
does not increase calving and that it probably will not influence the time of a new closure significantly.

\section{REFERENCES}

Field, W. O. 1975. Glaciers of the St Elias Mountains. In Field, W.O., ed. Mountain glaciers of the Northern Hemisphere. Volume 2. Hanover, NH, CRREL, 143-297.

Krimmel, R.M. and L.A. Rasmussen. 1986. Using sequential photography to estimate ice velocity at the terminus of Columbia Glacier, Alaska. Ann. Glaciol., 8, 117-123.

Krimmel, R. M. and B.H. Vaughn. 1987. Columbia
Glacier, Alaska: changes in velocity 1977-1986. $\mathcal{J}$. Geophys. Res., 92(B9), 8961-8968.

Mayo, L. R. 1988. Advance of Hubbard Glacier and closure of Russell Fiord, Alaska - environmental effects and hazards in the Yakutat area. U.S. Geol. Surv. Circ. 1016, 4-16.

Trabant, D. C., R. M. Krimmel and A. Post. 1991. A preliminary forecast of the advance of Hubbard Glacier and its influence on Russell Fiord, Alaska. U.S. Geol. Surv. Water-Resources Investigation Report 904172 .

The accuracy of references in the text and in this list is the responsibility of the author/s, to whom queries should be addressed. 